\title{
Primary soft tissue Ewing's sarcoma of the maxillary sinus in elderly patients: presentation, management and prognosis
}

\author{
Mainak Dutta ${ }^{1}$, Ms, Soumya Ghatak², Ms, Gautam Biswas ${ }^{3}$, MS, Arya Sen ${ }^{4}$, MD
}

\begin{abstract}
Nonosseous or soft tissue Ewing's sarcoma is a rare form of Ewing's sarcoma/primitive neuroectodermal tumour that seldom affects the head and neck region. Involvement of the nose and paranasal sinuses is extremely uncommon, with only eight of such patients being reported to date, mostly affecting adolescents and young adults. To our knowledge, this study is the first comprehensive report of primary soft tissue Ewing's sarcoma involving the paranasal sinuses in an elderly patient who successfully completed treatment. We herein discuss the pathogenesis, management and factors affecting the prognosis of this rare group of tumours involving the nose and paranasal sinuses, in relation to the available literature.
\end{abstract}

Keywords: elderly, Ewing's sarcoma family tumours, maxillary sinus, paranasal sinuses, soft tissue Ewing's sarcoma

\section{INTRODUCTION}

Extraosseous Ewing's sarcoma (ES) is a rare variety of the Ewing's sarcoma family of tumours (ESFTs) that arises from the soft tissues of the body. Involvement of the head-neck region in soft tissue Ewing's sarcoma (STES) is rare, and the nose and paranasal sinuses form exceedingly unusual sites for this tumour. We present here a comprehensive description of a primary STES of the maxillary sinus in an elderly patient who had successfully completed treatment, while also focusing on the pathology and management of this rare disorder.

\section{CASE REPORT}

A 67-year-old man presented with an insidious-onset, gradually progressive painful swelling over his left cheek (Fig. 1), which was noticed nearly three months previously. The pain, which was initially constant and dull, had been of severe burning nature for the preceding month.

On clinical examination, the lesion was firm, tender, approximately $5 \mathrm{~cm} \times 6 \mathrm{~cm}$ in size, and appeared lobulated, with ill-defined margins. It was fixed to the underlying structures but the overlying skin was free. Although the infraorbital region was mildly oedematous and hypoaesthetic, the infraorbital rim and lateral margin of the maxilla were clearly palpable in continuity. There was no history of nasal obstruction, epiphora, discharge or epistaxis. Affected by the mass, the patient had difficulty in opening his left eye, which had a narrow palpebral fissure. However, ocular movements and visual acuity were normal. On anterior rhinoscopy and subsequent nasoendoscopy, the left nasal cavity was found to be free from any lesion. Oral examination revealed edentulous jaws with normal alveolar thickness and no mucosal erosion. The left upper gingivobuccal sulcus and hard palate were not involved, and there were no palpable neck nodes.

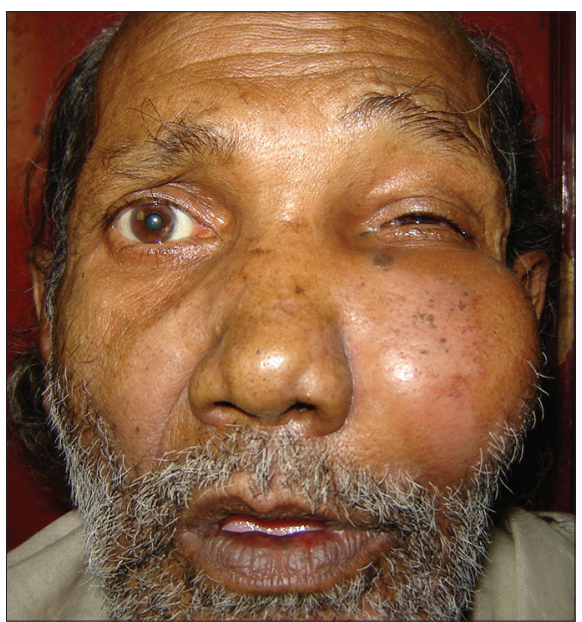

Fig. 1 Photograph shows a huge swelling over the left side of the cheek. Note the narrowed palpebral fissure and difficulty in opening the left eye.

Computed tomography (CT) of the nose and paranasal sinuses (Figs. 2a-c) revealed a non-enhancing homogeneous mass occupying the entire left maxillary sinus that had eroded through the anterolateral wall to involve the superficial soft tissues. The maxillary sinus walls on the left side were bulged compared to the contralateral side. However, bony integrity was maintained on all sides, including the orbital floor and lateral nasal wall. The nasal cavity was not involved, although there was bulging of the medial wall of the maxilla. The right maxillary sinus had homogeneous opacities, which is suggestive of nonspecific retained secretions detected incidentally.

A biopsy specimen was taken from the left maxillary sinus through a middle meatal antrostomy, which revealed sheets of small, round, uniform cells with indistinct cytoplasm, round-to-oval hyperchromatic nuclei, finely granular chromatin pattern and inconspicuous nucleoli, with few atypical mitoses (Fig. 3a). The histological findings

${ }^{1}$ Department of Otorhinolaryngology and Head-Neck Surgery, Medical College and Hospital, ${ }^{2}$ Department of Otorhinolaryngology and Head-Neck Surgery, R G Kar Medical College and Hospital, Kolkata, ${ }^{3}$ Department of Otorhinolaryngology and Head-Neck Surgery, ${ }^{4}$ Department of Pathology, Murshidabad Medical College and Hospital, Murshidabad, India Correspondence: Dr Mainak Dutta, Resident Medical Officer-cum-Clinical Tutor, Department of Otorhinolaryngology and Head-Neck Surgery, Medical College and Hospital, 88, College Street, Kolkata 700073, West Bengal, India. duttamainak@yahoo.com 

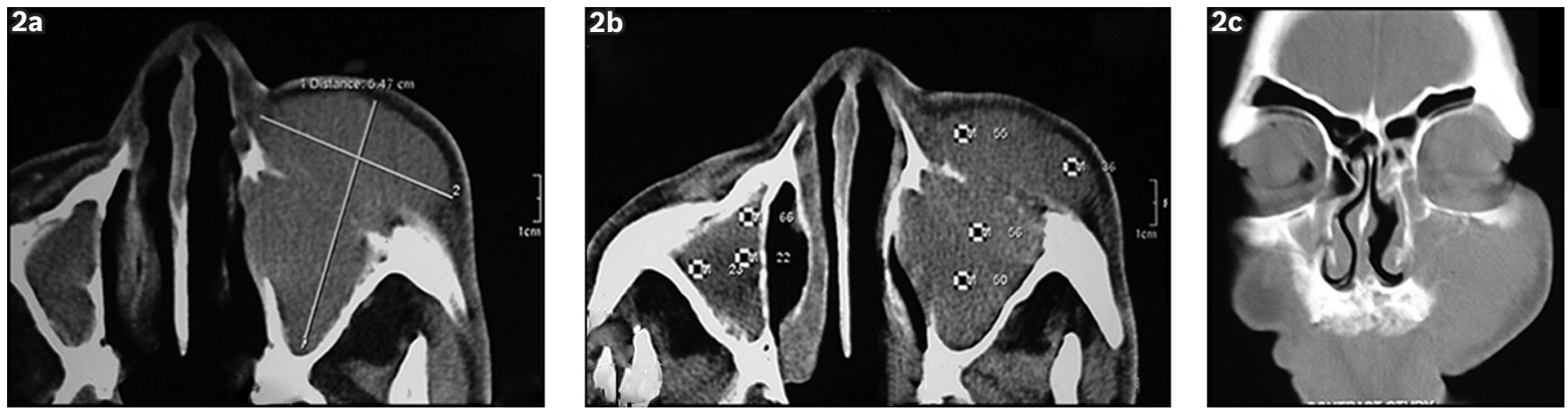

Fig. 2 (a \& b) Axial and (c) contrast-enhanced coronal CT images of the nose and paranasal sinuses show a nonenhancing mass occupying the entire left maxillary antrum, resulting in its marked bulging in comparison to the opposite side. All the walls except the anterolateral wall are intact. The nasal cavity in the left is not involved.
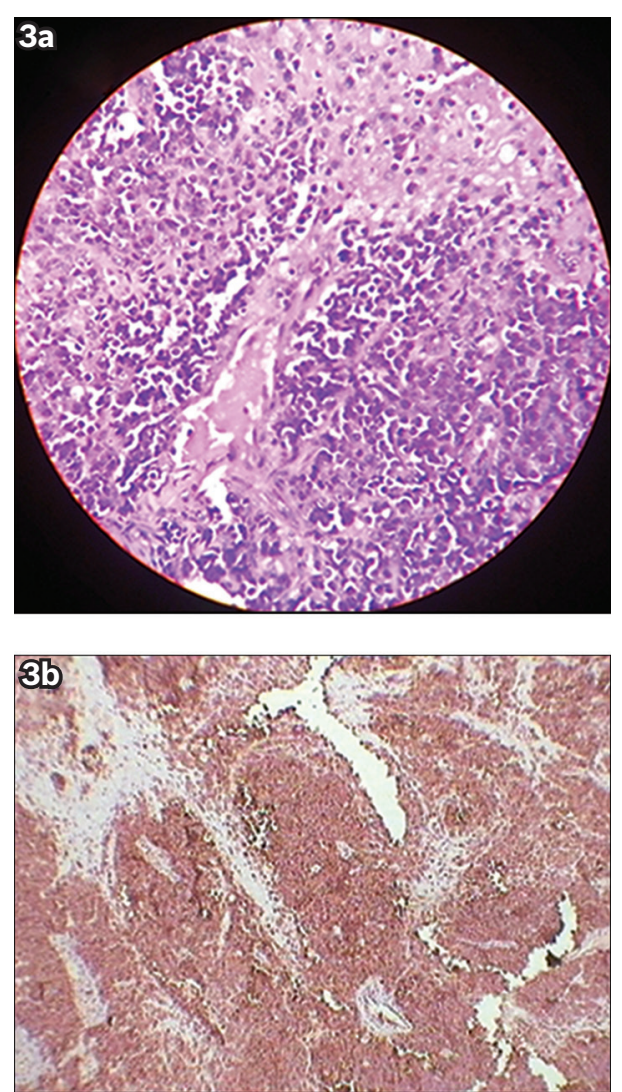

Fig. 3 Photomicrographs of the biopsy specimen. (a) Sheets of small, round, uniform cells with indistinct cytoplasm, round-to-oval hyperchromatic nuclei, finely granular chromatin pattern and inconspicuous nucleoli, and few atypical mitoses are seen (Haematoxylin \& eosin, $\times 400$ ). (b) Immunohistochemistry was strongly and diffusely positive for CD99, with a distinct cytoplasmic membrane pattern.

were highly suggestive of ES. Histochemical analysis using Periodic acid-Schiff (PAS) staining revealed diastase-sensitive glycogen in the cytoplasm. The differential diagnosis for small round cell neoplasms included rhabdomyosarcoma, malignant lymphoma, olfactory or secondary neuroblastoma etc. However, a diagnosis of ES was confirmed following immunohistochemical analysis that was strongly and diffusely positive for the CD99 antigen (Cluster of differentiation 99 or MIC-2), with a distinct cytoplasmic membrane pattern (Fig. 3b). This finding was supported by cytogenetic studies $[t(11 ; 22)$ translocation] for $\mathrm{ES}$. There was negative reaction for desmin, keratin, leucocyte common antigen (CD45 or LCA),

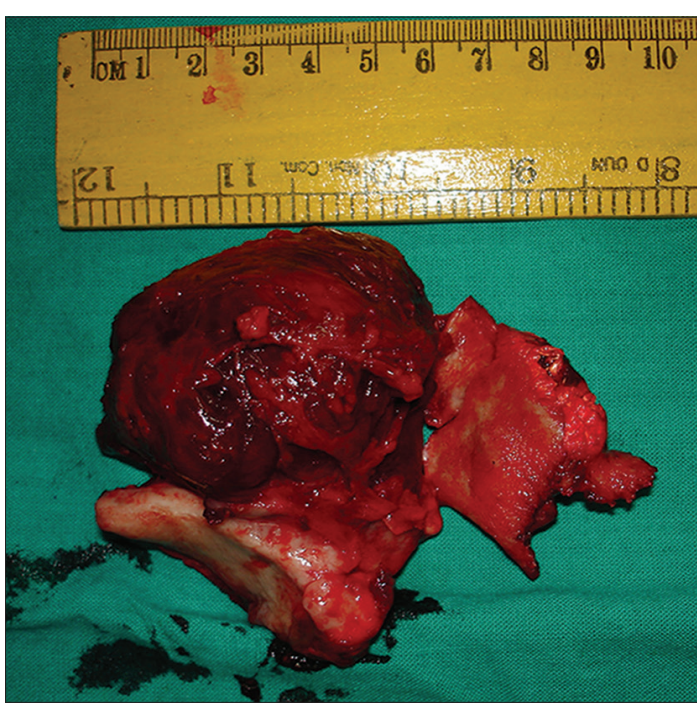

Fig. 4 Photograph shows the excised specimen, measuring $6 \mathrm{~cm} \times 5.5 \mathrm{~cm} \times 4 \mathrm{~cm}$.

neuron-specific enolase (NSE) and synaptophysin. A final diagnosis of primary STES arising from the left maxillary sinus was made, as subsequent whole-body bone scan with ${ }^{99 \mathrm{~m} T c}$ and CT of the thorax and abdomen failed to reveal any primary or metastatic focus.

Routine investigations were normal and the patient had no major comorbidity. Following satisfactory preanaesthetic evaluation, a total maxillectomy of the left side was planned. The standard Weber-Fergusson approach was adopted. The excised specimen measured approximately $6 \mathrm{~cm} \times 5.5 \mathrm{~cm} \times 4 \mathrm{~cm}$ (Fig. 4). A previously prepared palatal prosthesis was implanted for the patient. Histopathology of the excised specimen confirmed the diagnosis of primary STES from the left maxillary sinus. The surgical margin was found to be clear.

The patient recuperated satisfactorily and was started on adjuvant chemoradiation. The chemotherapy regimen consisted of vincristine $\left(1.4 \mathrm{mg} / \mathrm{m}^{2}\right)$, doxorubicin $\left(75 \mathrm{mg} / \mathrm{m}^{2}\right)$ and cyclophosphamide $\left(1.2 \mathrm{~g} / \mathrm{m}^{2}\right)$, alternating with ifosfamide $\left(1.2 \mathrm{~g} / \mathrm{m}^{2}\right.$; along with MESNA) and etoposide $\left(100 \mathrm{mg} / \mathrm{m}^{2}\right)$, given every three weeks for a total of 17 cycles. Following four cycles of chemotherapy, radiotherapy was administered for local control of the disease (180 cGy/fraction for 25 fractions [total dose of 45 Gy]). No major complications were noticed in the patient during and following chemoradiation. 
At two-year follow-up after completion of treatment, the patient was doing well without any evidence of recurrence at the primary site or any distant metastasis.

\section{DISCUSSION}

ESFT is the collective term often applied for the highly lethal ES/primitive neuroectodermal tumour (PNET) spectrum and is an important differential diagnosis of small round blue cell mesenchymal tumours (SRBCTs). ES is the second most common primary malignancy of the bone, typically affecting the paediatric and adolescent population ${ }^{(1)}$ in the age group of 5-30 years. It is a tumour of the extremities, and unless otherwise specified, it bears the notion that it arises from bones, especially the long bones, and also from the pelvis and ribs. ${ }^{(1)}$

Angervall and Enzinger ${ }^{(2)}$ introduced the term extraosseous STES as an entity over five decades after Ewing first described ES as a "diffuse endothelioma of bone" in 1921.(3) In their pioneering work, they provided detailed histological characteristics of 39 soft tissue tumours that resembled ES. Since then, ES has often been classified into osseous or skeletal ES (SES) and STES.

The origin and aetiopathogenesis of ES are not clear. Being a poorly differentiated tumour, its mesenchymal or neuroectodermal origin remains controversial. STES and SES exhibit identical histopathological, immunohistochemical and cytogenetic features. ${ }^{(4,5)}$ Both demonstrate the typical small round cells, with glycogen-rich (PAS-positive) scanty cytoplasm, increased nuclear-to-cytoplasmic ratio, round nuclei with fine granular chromatin, ${ }^{(1)}$ surface expression of CD99 and antibodies to the Friend leukaemia integration 1 transcription factor $(F L / 1)$ gene present in the nuclei, and a characteristic translocation at $\mathrm{t}(11 ; 22)(\mathrm{q} 24 ; \mathrm{q} 12)$, which is seen in $85 \%$ of patients and results in a chimeric fusion transcript, EWS-FLI1. (1) This specific translocation and the fusion transcript are pivotal in differentiating ES from other members of the SRBCT family of epithelial (including the poorly differentiated squamous cell carcinoma and sinonasal undifferentiated carcinoma), mesenchymal (including rhabdomyosarcoma and synovial sarcoma), neuroectodermal (including olfactory neuroblastoma and mucosal malignant melanoma) and haematolymphoid (including extramedullary plasmacytoma and extranodal NK/T cell lymphoma) lineages that are known to involve the sinonasal area. ${ }^{(6)}$ This is because CD99 positivity, although effective in differentiating the ES/ PNET group from most SRBCTs, may also be present in a few other tumours such as sinonasal desmoplastic small round cell tumour, synovial sarcoma or the more common lymphoma that shows considerable overlap on histology and ultrastructure. ${ }^{(6)}$ This underscores the importance of performing molecular cytogenetic studies as part of immunohistochemical analyses in addition to routine histopathology evaluations for the proper diagnosis of SRBCTs.

Despite similarities between SES and STES at the ultrastructural level, STES differs in its clinical presentation. Unlike SES, STES originates from the soft tissues, which may cause secondary bone erosion. It also tends to affect older patients. While SES seldom occurs to patients after the age of 30 years, ${ }^{(1)}$ nearly $35 \%-40 \%$ of patients with STES in some recent long-duration studies ${ }^{(2,7-9)}$ were aged over 30 years. Angervall and Enzinger's original report, ${ }^{(2)}$ as well as a recent study by Martin and Brennan, ${ }^{(7)}$ suggested that STES mostly affects the trunk (including the paraspinal region, and the anterior and posterior chest wall) rather than the extremities (Table I). However, for both SES and STES, the head and neck regions are the least affected. While the skeletal variety accounts for only $2 \%-3 \%$ of head-neck tumours, ${ }^{(10)}$ our review of the recent literature spanning nearly two decades revealed that STES was even rarer (Table I). The involvement of the nose and paranasal sinuses in primary STES was extremely rare, with only a handful of such patients reported in the literature. . $^{(4,5,8,10-13)}$ Further information on these reports can be found in Table II.

Our patient, a 67-year-old man diagnosed with primary extraosseous STES of the maxillary sinus, had successfully completed treatment and is presently being followed up without evidence of recurrence and dissemination. A thorough search of the literature indexed in the PubMed/MEDLINE database and the HighWire archives using the keywords 'soft tissue', 'Ewing's sarcoma', 'nose', 'paranasal sinuses' and 'elderly' revealed that none of the eight patients reported to have STES in the nose and paranasal sinuses were aged over 60 years. Our present case report is the ninth reported case of STES of the paranasal sinuses, the second reported case of STES of the paranasal sinuses without involvement of the nasal cavity (Coskun et al ${ }^{(13)}$ have previously reported one such patient) and the first comprehensive report of STES of the paranasal sinuses in an elderly patient who has successfully completed treatment. The only other patient aged over 50 years died from possible complications of chemotherapy midway through his treatment (Table II). ${ }^{(8)}$

Given the rarity of the lesion among elderly patients, patient age is significant as a predictor for survival. Although STES is seen relatively more in adult patients (patients were aged over 16 years in the study by Martin and Brennan, ${ }^{(7)}$ and over 12 years in the report by Lee et $\left.\mathrm{al}^{(9)}\right)$, its incidence among elderly patients is exceedingly rare. For instance, in the largest case series of adult patients with ESFT, Fizazi et al found that only seven out of a total of 182 patients were aged over 40 years. ${ }^{(14)}$ Similarly, only one patient was aged over 50 years in a group of 59 in the study by Verrill et al. ${ }^{(15)}$ To our knowledge, the only other study to have reported STES in five adult patients aged $\geq 50$ years described only one patient with primary STES of the paranasal sinus. ${ }^{(8)}$ The present study, which describes primary STES of the paranasal sinuses in a 67-year-old patient, is therefore novel.

Age as a predictor of survival has also been controversial. Although age at presentation ( $\geq 15$ years) was an independent adverse prognostic factor determining five-year disease-free survival in a cohort study by the European Intergroup Cooperative Ewing's Sarcoma Study Group of 975 patients with SES, ${ }^{(16)}$ many other studies have concluded that age is not an important factor that influences survival. ${ }^{(7-9,15)}$ Various authors have instead 
Table I. Summary of recent long-term studies on soft tissue Ewing's sarcoma in adult patients in the indexed literature, with emphasis on patients having head-neck involvement.

\begin{tabular}{|c|c|c|c|c|}
\hline \multirow[t]{2}{*}{ Characteristics } & \multicolumn{4}{|c|}{ Study (year) } \\
\hline & $\begin{array}{l}\text { Angervall and } \\
\text { Enzinger }^{(2)}(1975)\end{array}$ & $\begin{array}{l}\text { Martin and Brennan(7) } \\
(2003)\end{array}$ & $\begin{array}{l}\text { Bar-Sela et } a^{(8)} \\
(2008)\end{array}$ & Lee et $\mathrm{al}^{(9)}(2010)$ \\
\hline \multicolumn{5}{|l|}{ Patient demographics } \\
\hline Total no. of patients & 39 & 59 & 5 & 27 \\
\hline Patients aged > 30 yrs (\%) & 15 & 35.6 & NA & 40.7 \\
\hline Sites of involvement & $\begin{array}{l}\mathrm{T}>\mathrm{LE}>\mathrm{RP}=\mathrm{P}> \\
\mathrm{UE}=\mathrm{HN}\end{array}$ & $\begin{array}{l}\mathrm{T}>\mathrm{P}=\mathrm{LE}>\mathrm{UE} \\
>\mathrm{RP}>\mathrm{GU}>\mathrm{HN}\end{array}$ & $\mathrm{T}>\mathrm{GU}>\mathrm{HN}$ & $\mathrm{LE}>\mathrm{T}>\mathrm{UE}>\mathrm{HN}$ \\
\hline \multicolumn{5}{|l|}{ Head-neck involvement } \\
\hline No. of patients & 1 & 1 & 1 & 1 \\
\hline Age of patients (yrs) & 25 & $N G$ & 59 & $N G$ \\
\hline
\end{tabular}

*Age is presented as range, median (range) or mean \pm standard deviation. GU: genitourinary; HN: head-neck; LE: lower extremity; NA: not applicable; NG: not given; P: pelvis (including buttock region); RP: retroperitoneum; T: trunk (including the paravertibral region and chest wall); UE: upper extremity; USA: United States of America

Table II. Documented patients with primary soft tissue Ewing's sarcoma of the nose and paranasal sinuses in the indexed literature.

\begin{tabular}{|c|c|c|c|c|c|}
\hline Study (year) & Age (yrs)/gender & Site of involvement & $\begin{array}{l}\text { Histochemical } \\
\text { findings }\end{array}$ & $\begin{array}{l}\text { Immunohistochemical } \\
\text { investigation }\end{array}$ & Treatment \\
\hline $\begin{array}{l}\text { Pontius and Sebek }{ }^{(5)} \\
\text { (1981) }\end{array}$ & $39 / M$ & Left nasal fossa & $\begin{array}{l}\text { PAS +ve } \\
\text { (glycogen) }\end{array}$ & - & $\begin{array}{l}\text { Craniofacial } \\
\text { resection + RT }\end{array}$ \\
\hline $\begin{array}{l}\text { Lane and Ironside }{ }^{(11)} \\
\text { (1990) }\end{array}$ & $7 / M$ & $\begin{array}{l}\text { Right nasal cavity, } \\
\text { ethmoid, orbita }\end{array}$ & $\begin{array}{l}\text { PAS +ve } \\
\text { (glycogen) }\end{array}$ & Vimentin & $\begin{array}{l}\text { Partial intranasal } \\
\text { ethmoidectomy }\end{array}$ \\
\hline $\begin{array}{l}\text { Howard and Daniels }{ }^{(10)} \\
(1993)\end{array}$ & $14 / M$ & $\begin{array}{l}\text { Ethmoid sinuses, right } \\
\text { nasal cavity }\end{array}$ & Reticulin +ve & - & $\begin{array}{l}\text { Craniofacial resection + } \\
\mathrm{CT}+\mathrm{RT}\end{array}$ \\
\hline $\begin{array}{l}\text { Howard and Daniels }{ }^{(10)} \\
(1993)\end{array}$ & $28 / F$ & Nose & Reticulin +ve & - & $\begin{array}{l}\text { Partial rhinectomy + } \\
\mathrm{RT}+\mathrm{CT}\end{array}$ \\
\hline $\begin{array}{l}\text { Böör et al|(12) } \\
(2001)\end{array}$ & $20 / F$ & Nose & $\begin{array}{l}\text { PAS +ve } \\
\text { (glycogen) }\end{array}$ & CD99 & Surgery + CT + RT \\
\hline $\begin{array}{l}\text { Aferzon et } \mathrm{al}^{(4)} \\
(2003)\end{array}$ & $14 / F$ & Ethmoids & - & CD99 & $\begin{array}{l}\text { Anterior and posterior } \\
\text { ethmoidectomies + CT } \\
+\mathrm{RT}\end{array}$ \\
\hline $\begin{array}{l}\text { Coskun et al } \mathrm{l}^{(13)} \\
(2005)\end{array}$ & $16 / F$ & $\begin{array}{l}\text { Right maxillary sinus + } \\
\text { orbita }\end{array}$ & $\begin{array}{l}\text { PAS +ve } \\
\text { (glycogen) }\end{array}$ & CD99 & $\mathrm{CT}+\mathrm{RT}$ \\
\hline $\begin{array}{l}\text { Bar-Sela et al }{ }^{(8)} \\
(2008)\end{array}$ & $59 / M^{*}$ & $\begin{array}{l}\text { Right maxillary sinus, } \\
\text { penetrating into the nasal } \\
\text { cavity and right orbit }\end{array}$ & NA & NA & CT (incomplete) \\
\hline $\begin{array}{l}\text { Present study } \\
\text { (2013) }\end{array}$ & $67 / M$ & $\begin{array}{l}\text { Left maxillary sinus + } \\
\text { superficial soft tissue of } \\
\text { cheek }\end{array}$ & $\begin{array}{l}\text { PAS +ve } \\
\text { (glycogen) }\end{array}$ & CD99 & $\begin{array}{l}\text { Right total maxillectomy } \\
+\mathrm{CT}+\mathrm{RT}\end{array}$ \\
\hline
\end{tabular}

*The patient, who had comorbidities such as chronic ischaemic heart disease and paraplegia, died during treatment possibly due to complications arising from chemotherapy. +ve: positive; CD99: Cluster of differentiation 99 antigen; CT: chemotherapy; F: female; M: male; NA: not available; PAS: Periodic acid-Schiff; $\mathrm{RT}$ : radiotherapy

presented the presence of metastasis ${ }^{(7,9)}$ and tumour volume ${ }^{(9)}$ as independent risk factors of disease-free survival. Our patient, who did not have metastasis at presentation, did not develop any subsequently as well. With a maximum diameter of $6 \mathrm{~cm}$ (tumour volume $\sim 113 \mathrm{~mL}$ ), the tumour in our patient would be deemed to be intermediate in size according to the description by Martin and Brennan. ${ }^{(7)}$ While Lee et al suggested that tumour volume greater than $200 \mathrm{~mL}$ adversely affected survival outcome, ${ }^{(9)}$ Martin and Brennan ${ }^{(7)}$ found no difference in the survival outcomes of patients with tumour volume greater than $100 \mathrm{~mL}$ compared to those with tumour volume less than $100 \mathrm{~mL}$. This may explain the good outcomes seen in our patient, even though his old age and large tumour size were factors generally reported to result in poorer prognosis for adult-onset ESFTs. ${ }^{(8)}$

Given that the literature on primary STES of the nose and paranasal sinuses is scarce, diagnostic approaches for STES in the head-neck region have not been standardised, unlike those for STES at other sites such as the trunk. Available 
data suggests that STES in the paranasal sinuses arises from the soft tissues in the region. Conversely, studies have also considered ES at this subsite as STES, ${ }^{(5)}$ and also ES of the nose and ethmoids as STES. ${ }^{(4,10,12)}$ The diagnosis and distinction of STES from SES of the maxilla/zygoma are usually made on the basis of clinical presentation and radiology. In our patient, the infraorbital rim, gingivobuccal sulcus and hard palate were found to be clinically intact. On $\mathrm{CT}$, the left maxillary sinus was disproportionately bulged, but with intact walls apart from its anterolateral wall. STES is known to erode adjacent bones, and patients with eroded orbita and lateral nasal wall have been reported. ${ }^{(8,10)}$

Treatment of ESFT in the head-neck region primarily consists of a combination of surgery, chemotherapy and radiotherapy. ${ }^{(11)}$ As the general condition and preoperative investigations were favourable for our patient, he was offered surgery followed by chemoradiation. ESFTs are highly radiosensitive. ${ }^{(8}$ Chemotherapy, including induction and neoadjuvant regimens, in addition to surgery, formed the mainstay of treatment in the study by Martin and Brennan. ${ }^{(7)}$ On the other hand, in light of the small number of such tumours reported in adult patients and the absence of a set treatment protocol, some authors have approached older patients with STES using conventional adjuvant chemotherapy as well. ${ }^{(7)}$ While a proper and universal treatment protocol is needed for STES in the head-neck region, it might take a while to develop such regimes, as the relative rarity of ESFTs, especially among the Asian population, is a major cause of inadequate cohort strength. ${ }^{(9)}$

In conclusion, extraosseous STES is a rare variant in the ES/PNET spectrum. It is identical to SES on histopathology, immunohistochemistry and molecular cytology, but has varied clinical presentation and radiological features. STES in the head-neck region is extremely rare, and STES in the nose and paranasal sinuses are seldom reported as a primary site. Treatment, which mainly consists of surgery and chemoradiation, should be opted for based on suitability for adult, and especially elderly, patients. In this study, we reported primary STES involving the paranasal sinuses in an elderly patient who successfully completed treatment, and discussed the pathogenesis, management and prognosis of this rare group of tumours in the head-neck region.

\section{REFERENCES}

1. Ushigome S, Machinami R, Sorensen PH. Ewing Sarcoma/Primitive Neuroectodermal Tumour (PNET). In: Fletcher CD et al, eds. Pathology and Genetics of Tumours of Soft Tissue and Bone. World Health Organization Classification of Tumours. Lyon: IARC Press, 2002: 298-300.

2. Angervall L, Enzinger FM. Extraskeletal neoplasm resembling Ewing's sarcoma. Cancer 1975; 36:240-51.

3. Ewing J. Diffuse endothelioma of bone. Proc N Y Pathol Soc 1921; 21:17-24.

4. Aferzon M, Wood WE, Powell JR. Ewing's sarcoma of the ethmoid sinus. Otolaryngol Head Neck Surg 2003; 128:897-901.

5. Pontius KI, Sebek BA. Extraskeletal Ewing's sarcoma arising in the nasal fossa. Light-electron microscopic observations. Am J Clin Pathol 1981; 75:410-5.

6. Bridge JA, Bowen JM, Smith RB. The small round blue cell tumors of the sinonasal area. Head and Neck Pathol 2010; 4:84-93.

7. Martin RC 2nd, Brennan MF. Adult soft tissue Ewing sarcoma or primitive neuroectodermal tumors: predictors of survival? Arch Surg 2003; 138:281-5.

8. Bar-Sela G, Peer A, Rothschild S, Haim N. Treatment of patients aged over 50 years with non-osseous Ewing's sarcoma family tumors: five cases and review of literature. Tumori 2008; 94:809-12.

9. Lee JA, Kim DH, Lim JS, et al. Soft-tissue Ewing sarcoma in a lowincidence population: comparison to skeletal ewing sarcoma for clinical characteristics and treatment outcome. Jpn J Clin Oncol 2010; 40:1060-7.

10. Howard DJ, Daniels HA. Ewing's sarcoma of the nose. Ear Nose Throat J 1993; 72:277-79.

11. Lane S, Ironside JW. Extraskeletal Ewing's sarcoma of the nasal fossa. J Laryngol Otol 1990; 104:570-3.

12. Böör A, Jurkovic I, Friedmann I, Plank L, Kocan P. Pathology in focus. Extraskeletal Ewing's sarcoma of the nose. J Laryngol Otol 2001; 115:74-6.

13. Coskun BU, Cinar U, Savk H, Basak T, Dadas B. Isolated maxillary sinus Ewing's sarcoma. Rhinology 2005; 43:225-8.

14. Fizazi K, Dohollou N, Blay JY, et al. Ewing's family of tumors in adults: multivariate analysis of survival and long-term results of multimodality therapy in 182 patients. J Clin Oncol 1998; 16:3736-43.

15. Verrill MW, Judson IR, Harmer CL, et al. Ewing's sarcoma and primitive neuroectodermal tumor in adults: are they different from Ewing's sarcoma and primitive neuroectodermal tumor in children. J Clin Oncol 1997; 15:2611-21.

16. Cotterill SJ, Ahrens S, Paulussen M, et al. Prognostic factors in Ewing's tumor of bone: analysis of 975 patients from the European Intergroup Cooperative Ewing's Sarcoma Study Group. J Clin Oncol 2000; 18:3108-14. 